\title{
Barriers to use of modern contraceptives among women in an inner city area of Osogbo metropolis, Osun State, Nigeria
}

This article was published in the following Dove Press journal:

International Journal of Women's Health

10 October 2013

Number of times this article has been viewed

\section{EO Asekun-Olarinmoye' \\ WO Adebimpe' \\ JO Bamidele ${ }^{2}$ \\ OO Odu² \\ IO Asekun-Olarinmoye ${ }^{3}$ \\ EO Ojofeitimi ${ }^{4}$}

'Department of Community Medicine, Faculty of Clinical Sciences, Osun State University, Osogbo, Osun State, Nigeria; ${ }^{2}$ Department of Community Medicine, Faculty of Clinical Sciences, Ekiti State University, Ado-Ekiti, Ekiti State, Nigeria; ${ }^{3}$ Department of Community Health, School of Public and Allied Health, Babcock University, Ilishan-Remo, Ogun State, Nigeria; ${ }^{4}$ Department of Community Medicine, Faculty of Clinical Sciences, Ladoke Akintola University of Technology, Osogbo, Osun State, Nigeria
Correspondence: EO Asekun-Olarinmoye Department of Community Medicine, College of Health Sciences, Faculty of Clinical Sciences, Osun State University, PMB 4494, Osogbo, Osun State, Nigeria Email gmjfunmilayo@gmail.com; esther. asekun-olarinmoye@uniosun.edu.ng
Objectives: To determine the knowledge and attitudes on modern contraceptive use of women living in an inner city area of Osogbo.

Materials and methods: Three hundred and fifty nine women of childbearing age were studied utilizing a community-based, descriptive, cross-sectional study design. A multistage random sampling technique was used in recruiting respondents to the study. A four-part questionnaire was applied dually, by interviewers and by respondents' self administration, and the data was analyzed using the SPSS software version 17.0.

Results: The mean age of respondents was $28.6 \pm 6.65$ years. The majority $(90.3 \%)$ of respondents were aware of modern methods of family planning (FP), $76.0 \%$ claimed awareness of where to obtain FP services, and $74.9 \%$ knew of at least five methods. However, only $30.6 \%$ had ever used contraceptives, while only $13.1 \%$ were current users. The most frequently used method was the male condom. The commonly perceived barriers accounting for low use of FP methods were fear of perceived side effects $(44.0 \%)$, ignorance $(32.6 \%)$, misinformation (25.1\%), superstition $(22.0 \%)$, and culture $(20.3 \%)$. Some reasons were proffered for respondents' nonuse of modern contraception. Predictors of use of modern contraceptives include the awareness of a place of FP service provision, respondents' approval of the use of contraceptives, higher education status, and being married.

Conclusion: Most of the barriers reported appeared preventable and removable and may be responsible for the reported low point prevalence of use of contraceptives. It is recommended that community-based behavioral-change communication programs be instituted, aimed at improving the perceptions of women with respect to bridging knowledge gaps about contraceptive methods and to changing deep-seated negative beliefs related to contraceptive use in Nigeria.

Keywords: childbearing age, family planning, fertility desires, perception, knowledge, attitude, benefits

\section{Introduction}

Increasing the level of contraceptive use among women of child bearing age is an important component of many national population and developmental programs in sub-Saharan Africa; however the prevalence use of these methods is still low despite the efforts of many governmental and nongovernmental agencies (NGOs). ${ }^{1}$ Globally, unplanned pregnancies and sexually transmitted infections (STIs) persist as significant threats to women's reproductive health. ${ }^{2}$ Barriers to the use of modern contraceptives by women might inhibit uptake of novel woman-controlled methods for preventing unwanted pregnancies and STIs/human immunodeficiency virus (HIV). Illegal abortions arising from unwanted pregnancies constitute a major reproductive 
health problem in Nigeria. Data indicate that the proportion of women having unwanted pregnancies in this country is increasing: women and couples increasingly want fewer children, and although they are also beginning to bear fewer children, behavior is lagging behind preference. ${ }^{3,4}$ Thus women and couples are increasingly having more children than they want.

Since abortion is illegal under most conditions in Nigeria, an increase in the incidence of unwanted pregnancy is likely to result in a rise in the incidence of unsafe abortions. This in turn, is likely to raise the proportion of women with abortion-related morbidity and mortality. The increasing incidence of complications from unsafe abortions can have a substantial impact on the country's fragile health system. The use of "modern" contraceptive methods (oral pills, condoms, intrauterine devices, sterilization, implants, and injectables) has traditionally been low in sub-Saharan Africa, but there is evidence of an increase during the past decade..$^{5}$ During the 1990s, the self-reported use of modern contraceptives among married women increased in East Africa by $1 \%$ each year, to $17 \%$ by 1999 ; in West Africa, it increased by $0.5 \%$ each year, to $8 \%$ by $1999 .^{6}$

Huge resources have been committed to family planning (FP) programs by the stakeholders in reproductive health, however, communities are not usually involved in the planning and pre-implementation phases of programs, which would have encouraged their full participation and help to unravel the barriers to uptake of services. In addition, evidence as to how community-level contextual factors influence variations in the use of contraceptive methods is limited; this information could be useful, most especially in inner cities, where there are peculiar social and reproductive health problems, urbanization, and population growth and explosion. To date, most efforts at contraception have been health facility-based, while community-based distribution of contraceptives is still in the conceptual stage in Nigeria.

Knowledge, perceptions, attitudes towards contraceptive use, and barriers to use were investigated in this paper, with the aim of providing evidence-based data for stakeholders, including national governments, agencies, and NGOs, working on fertility reduction programs through contraception; these data can inform policy decision making and also serve as an advocacy tool, for a more coordinated and community-based approach in the design of programs that would remove barriers to use of modern contraceptives. This study determined the knowledge of and attitude toward modern contraceptive use, in women of childbearing age living in an inner city area of Osogbo.

\section{Materials and methods}

\section{Study area}

Osogbo is the capital of Osun State in the southwestern part of Nigeria. The town has a population of about 2.6 million, as per the last national census. ${ }^{7}$ In the inner city area of Osogbo metropolis, the majority of inhabitants are traders, artisans, and civil servants. There is a teaching hospital, a general hospital and numerous Primary Health Centers (PHCs), as well as mission and private hospitals providing care within the metropolis.

\section{Study design}

This was a community-based, descriptive cross-sectional study of barriers to the use of modern contraception among women of reproductive age in the inner city area of Osogbo metropolis.

\section{Study population}

The target populations were women of reproductive age, 15 to 49 years, living in the inner city area for at least 5 years. The women who responded to the research instruments constitute the study population.

\section{Sample size estimation}

Using the sample size calculation formula for the calculation of sample size greater than $10,000^{8}$ and a prevalence rate of $30.1 \%{ }^{9}$ for contraceptive utilization rate, the calculated sample size was 316 . This was increased to 332 after adjusting for a 5\% nonresponse rate; however, 380 respondents were surveyed.

\section{Sampling method}

A multistage sampling method was adopted in sample selection. In stage 1, a list of designated areas in the inner city area of Osogbo was obtained from the town planning unit of the State Ministry of Lands and Physical Planning. Fifty percent (four out of the eight areas) were selected by simple random sampling, employing simple balloting. A list of communities in each designated area was drawn in stage 2, and two were selected using simple random sampling (simple balloting). This evolved a total of eight inner city communities. Questionnaires were equally allocated to each community.

In stage 3, a sampling frame of all enumeration areas in each community was drawn. The enumeration areas used were allocated by the National Population Commission for the 2006 National population census. One enumeration area was selected per community using simple random sampling 
(simple balloting). In stage 4, a sample frame or list of all streets in an enumeration area was prepared, and two streets were chosen per enumeration area by simple random sampling employing simple balloting. On a street, the existing primary health care household numbering was utilized to select houses. Every house with the last number being an even number was selected, and the consenting women of child-bearing age therein participated in the completion of the research instrument until the allocated questionnaires for that community was exhausted.

\section{Data collection}

All eligible consenting women met in the sampled houses were interviewed with precoded, pretested, intervieweradministered questionnaires conducted by trained research assistants who could also speak the local language. A vernacular version of the questionnaire was prepared for the uneducated respondents, to reduce interobserver variation in interpretation during the interview. The questionnaire was translated and back-translated between the English and the local Yoruba language. Whenever a house was found to be empty, such houses were omitted, and the next even numbered house to it was selected to replace it. Data collection was conducted within a convenient period of 1 month. The study variables included information on the socioeconomic characteristics of the respondents, knowledge, attitude, the utilization of modern contraceptives, and barriers to use.

\section{Ethical consideration and limitation}

Ethical approval to conduct this study was obtained from the Research Ethics Committee of Ladoke Akintola University of Technology (LAUTECH) Teaching Hospital Osogbo. Approvals were also obtained from the Local Government Departments of Health and Community Development and the heads of selected communities. Verbal informed consent was obtained from each respondent.

\section{Data management}

The SPSS Version 17.0 (SPSS Inc., Chicago, IL, USA) statistical package was used for data entry and analysis. The validity of the data collected was ensured by double entry and by random checks for errors. Relevant frequency distributions tables and summary measures were generated. The Chi-square test was used to demonstrate relationships between categorical variables, and the level of significance was set at $P$-values $\leq 0.05$, at the confidence interval of $95 \%$, for all inferential analysis.

\section{Results}

A total of 380 respondents were surveyed, but only 359 questionnaires were adequately completed, giving a 94.0\% response rate. Table 1 shows the sociodemographic characteristics of the respondents. The mean age of respondents was $28.6 \pm 6.65$ years. At the time of survey, 265 (73.8\%) were "ever married," 194 (54.0) were Christians, and 278 (77.4\%) had at least a secondary level education.

Table 2 shows that $324(90.3 \%)$ respondents were aware of modern methods of FP, and 273 (76.0\%) of these claimed awareness of where to obtain FP services. Awareness of most modern contraceptives was very high among respondents. The most commonly mentioned contraceptive

Table I Sociodemographic characteristics of respondents

\begin{tabular}{|c|c|c|}
\hline \multirow{2}{*}{$\begin{array}{l}\text { Variables } \\
\text { Age }\end{array}$} & \multicolumn{2}{|c|}{$(N=359)$} \\
\hline & \multirow{2}{*}{\multicolumn{2}{|c|}{$28.59 \pm 6.7$ years }} \\
\hline Mean age & & \\
\hline Median age & \multicolumn{2}{|c|}{28.0 years } \\
\hline Modal age & \multicolumn{2}{|c|}{25.0 years } \\
\hline Age group in years & $\mathbf{N}$ & $\%$ \\
\hline$<20$ & 10 & 2.8 \\
\hline $20-24$ & 75 & 20.9 \\
\hline $25-29$ & $|3|$ & 36.5 \\
\hline $30-34$ & 65 & 18.1 \\
\hline $35-39$ & 32 & 8.9 \\
\hline $40-44$ & 19 & 5.3 \\
\hline $45-49$ & 11 & 3.0 \\
\hline No response & 16 & 4.5 \\
\hline \multicolumn{3}{|l|}{ Marital status } \\
\hline Single & 84 & 23.4 \\
\hline Married & 258 & 71.8 \\
\hline Divorced & 2 & 0.6 \\
\hline Widowed & 3 & 0.8 \\
\hline Separated & 2 & 0.6 \\
\hline No response & 10 & 2.8 \\
\hline \multicolumn{3}{|l|}{ Religion } \\
\hline Christianity & 194 & 54.0 \\
\hline Islam & 147 & 41.0 \\
\hline Others & 18 & 5.0 \\
\hline \multicolumn{3}{|l|}{ Educational status } \\
\hline No formal education & 25 & 7.0 \\
\hline Primary & 42 & 11.7 \\
\hline Secondary & 128 & 35.6 \\
\hline Tertiary & 150 & 41.8 \\
\hline No response & 14 & 3.9 \\
\hline \multicolumn{3}{|l|}{ Occupational status } \\
\hline Unemployed & 85 & 23.7 \\
\hline Unskilled employment & 118 & 32.9 \\
\hline Skilled employment & 62 & 17.3 \\
\hline Professional employment & 73 & 20.3 \\
\hline No response & 21 & 5.8 \\
\hline \multicolumn{3}{|l|}{ Type of marriage $(n=275)$} \\
\hline Monogamy & 222 & 80.7 \\
\hline Polygamy & 53 & 19.3 \\
\hline
\end{tabular}


Table 2 Respondents' awareness and knowledge about modern contraception

\begin{tabular}{|c|c|c|}
\hline Variables $(n=359)$ & $\mathbf{N}$ & $\%$ \\
\hline Awareness of modern contraceptive methods & 324 & 90.3 \\
\hline \multicolumn{3}{|l|}{ Types of modern contraceptive methods known } \\
\hline Male condoms & 328 & 91.4 \\
\hline Injectables & 295 & 82.2 \\
\hline Oral pills & 258 & 71.9 \\
\hline Female condoms & 235 & 65.5 \\
\hline Intrauterine device (IUD) & 320 & 64.1 \\
\hline Bilateral tubal ligation & 37 & 10.3 \\
\hline Spermicides & 12 & 3.3 \\
\hline Implants & 12 & 3.3 \\
\hline Awareness of health facility with service & 273 & 76.0 \\
\hline \multicolumn{3}{|l|}{ Cadre of health facility known to offer service $(n=273)$} \\
\hline Primary health care center & 11 & 4.0 \\
\hline Comprehensive health center & 76 & 7.8 \\
\hline General hospital & 37 & 13.6 \\
\hline Teaching hospital & 138 & 50.5 \\
\hline Planned Parenthood Federation of Nigeria & 9 & 3.3 \\
\hline Private hospital & 2 & 0.7 \\
\hline \multicolumn{3}{|l|}{ Distance of health facility to respondents' homes $(n=273)$} \\
\hline$<5 \mathrm{~km}$ & 146 & 53.5 \\
\hline $5-10 \mathrm{~km}$ & 89 & 32.6 \\
\hline $10-15 \mathrm{~km}$ & 34 & 12.5 \\
\hline $15-20 \mathrm{~km}$ & 4 & 1.5 \\
\hline \multicolumn{3}{|l|}{ Respondents' perceptions $(n=359)$} \\
\hline \multicolumn{3}{|l|}{ Perceived benefits of contraception } \\
\hline Child spacing & 228 & 63.5 \\
\hline Prevention of unwanted pregnancies & 215 & 59.9 \\
\hline Boost husband's fidelity (keeps husband at home) & 94 & 26.2 \\
\hline Improve family life & 85 & 23.7 \\
\hline Regulation of family size & 75 & 20.9 \\
\hline Prevention of sexually transmitted infections (STI) & 49 & 13.6 \\
\hline Improve mother and child health & 18 & 5.0 \\
\hline \multicolumn{3}{|l|}{ Perceived side effects of contraception } \\
\hline None & 50 & 13.9 \\
\hline Irregular menstruation & 212 & 59.1 \\
\hline Abdominal pain & 86 & 24.0 \\
\hline Headache & 80 & 2.3 \\
\hline Infertility & 76 & 21.2 \\
\hline Weight gain & 65 & 18.1 \\
\hline Ectopic pregnancy & 62 & 17.3 \\
\hline Sexual dissatisfaction & 57 & 15.9 \\
\hline Failure rate & 39 & 10.9 \\
\hline Cancer & 12 & 3.3 \\
\hline Others (eg, weight loss, leg pain, vomiting, irritation) & 76 & 21.2 \\
\hline
\end{tabular}

method known to the respondents was male condoms (328 [91.4\%]), followed by injectables (295 [82.2\%]) and oral pills (258 [71.9\%]). Many of the respondents were able to identify the common benefits and side effects of modern contraception. Among the most commonly cited benefits were child spacing $(63.5 \%)$ and prevention of unwanted pregnancies (59.9\%). However, the perceived side effects of modern contraceptives mentioned included irregular menstruation (59.1\%), abdominal pain (24.0\%), headache (22.3\%), and infertility (21.2\%).

Table 3 shows the reproductive history, fertility desires, contraceptive use, and perceived barriers to contraceptive use among the respondents. One hundred and forty-nine respondents $(41.5 \%)$ had at least two living children, while $14.5 \%$ had "ever lost" children. Most, 209 (58.1\%), of respondents wanted at least four or more children in their lifetimes, and

Table 3 Fertility desires, contraceptive use, and barriers to use among respondents

\begin{tabular}{|c|c|c|}
\hline Variables & $\mathbf{N}$ & $\%$ \\
\hline \multicolumn{3}{|c|}{ Respondents' reproductive history and fertility desires } \\
\hline \multicolumn{3}{|l|}{ Desired number of children $(n=359)$} \\
\hline 0 & 4 & 1.1 \\
\hline I & 23 & 6.4 \\
\hline $2-3$ & 118 & 32.9 \\
\hline 4 & 104 & 29.0 \\
\hline$>4$ & 105 & 29.2 \\
\hline No response & 5 & 1.4 \\
\hline \multicolumn{3}{|l|}{ Number of children alive $(n=359)$} \\
\hline None & 132 & 36.8 \\
\hline I & 78 & 21.7 \\
\hline 2 & 69 & 19.2 \\
\hline 3 & 44 & 12.3 \\
\hline 4 & 26 & 7.2 \\
\hline$>5$ & 10 & 2.8 \\
\hline \multicolumn{3}{|l|}{ Ever lost a child } \\
\hline Yes & 52 & 14.5 \\
\hline No & 307 & 85.5 \\
\hline \multicolumn{3}{|l|}{ Desire more children } \\
\hline Yes & 216 & 60.2 \\
\hline No & 143 & 39.8 \\
\hline \multicolumn{3}{|l|}{ Ever use modern contraception $(n=359)$} \\
\hline Yes & 110 & 30.6 \\
\hline No & 249 & 69.4 \\
\hline \multicolumn{3}{|l|}{ Current users of contraception $(n=359)$} \\
\hline Yes & 47 & 13.1 \\
\hline No & 312 & 86.9 \\
\hline \multicolumn{3}{|l|}{ Reasons for nonuse of contraception $(n=249)$} \\
\hline Desire for more children & 99 & 39.8 \\
\hline Fear of side effects/complications & 96 & 38.6 \\
\hline Ignorance & 66 & 26.5 \\
\hline $\begin{array}{l}\text { Perceived low-risk of getting pregnant/ } \\
\text { not sexually active }\end{array}$ & 38 & 15.3 \\
\hline Religion & 24 & 9.6 \\
\hline Partner/husband nonsupport/nonapproval & 9 & 3.6 \\
\hline \multicolumn{3}{|c|}{ Respondents' opinion of barrier factors to contraceptive use $(n=359)$} \\
\hline Fear of perceived side effects & 158 & 44.0 \\
\hline Ignorance & 117 & 32.6 \\
\hline Misinformation & 90 & 25.1 \\
\hline Superstition & 79 & 22.0 \\
\hline Culture & 73 & 20.3 \\
\hline Negative attitude & 46 & 12.8 \\
\hline Religion & 31 & 8.6 \\
\hline Illiteracy & 28 & 7.8 \\
\hline Partner nonsupport/nonapproval & 24 & 6.7 \\
\hline
\end{tabular}


$216(60.2 \%)$ reported desire for more children. The major reasons for wanting more children related to pressure from husband/relatives and the belief that child survival in Nigeria was not reliable. Only 110 (30.6\%) had ever used modern contraceptives, while only $47(13.1 \%)$ were current users. The most commonly stated reasons for not using contraception were the desire for more children (39.8\%), fear of side effects/complications (38.6\%), ignorance of contraceptive methods $(26.5 \%)$, and perception of low risk of getting pregnant (because they did not have sex regularly or were sexually inactive) (15.3\%), while nine (3.6\%) respondents claimed that their husband did not support contraceptive use. The most commonly perceived barriers of respondents accounting for low use of FP methods in the community were fear of perceived side effects $(44.0 \%)$, ignorance of contraceptive methods (32.6\%), misinformation (25.1\%), superstition $(22.0 \%)$, and culture $(20.3 \%)$.

The results showed that 284 (79.1\%) of respondents declared their support/approval for the use of modern contraception. The most frequently used method was the male condom.

Table 4 shows the attitudes of respondents towards modern contraceptive use. Although 277 (77.2\%) of the respondents

Table 4 Respondents' attitude to use of modern contraceptive methods $(n=359)$

\begin{tabular}{|c|c|c|c|}
\hline linal statements & $\begin{array}{l}\text { Agree } \\
\text { N (\%) }\end{array}$ & $\begin{array}{l}\text { Indecision } \\
\mathbf{N}(\%)\end{array}$ & $\begin{array}{l}\text { Disagree } \\
\mathbf{N}(\%)\end{array}$ \\
\hline $\begin{array}{l}\text { Religion is against the use } \\
\text { of family planning }\end{array}$ & $96(26.7)$ & $48(13.4)$ & $215(59.9)$ \\
\hline $\begin{array}{l}\text { Family planning encourages/ } \\
\text { promotes infidelity and } \\
\text { promiscuity }\end{array}$ & $127(35.4)$ & $79(22.0)$ & $153(42.6)$ \\
\hline $\begin{array}{l}\text { Family planning is good } \\
\text { for the mothers }\end{array}$ & $277(77.2)$ & $31(8.6)$ & $5 I(14.2)$ \\
\hline $\begin{array}{l}\text { Culture is against the use } \\
\text { of family planning }\end{array}$ & $77(21.4)$ & 81 (22.6) & $201(56.0)$ \\
\hline $\begin{array}{l}\text { Family planning methods } \\
\text { are not effective }\end{array}$ & $64(17.8)$ & 69 (19.2) & $226(63.0)$ \\
\hline $\begin{array}{l}\text { There are many side effects } \\
\text { of family planning methods } \\
\text { that are harmful }\end{array}$ & 138 (38.4) & $95(26.5)$ & $126(35.1)$ \\
\hline $\begin{array}{l}\text { Only women should use } \\
\text { family planning methods }\end{array}$ & II5 (32.0) & $39(10.9)$ & $205(57.1)$ \\
\hline $\begin{array}{l}\text { Men should also use family } \\
\text { planning methods }\end{array}$ & $263(73.3)$ & $37(10.3)$ & $59(16.4)$ \\
\hline $\begin{array}{l}\text { Husbands should allow their } \\
\text { wives to use family planning }\end{array}$ & $303(84.4)$ & $26(7.2)$ & $30(8.4)$ \\
\hline $\begin{array}{l}\text { Husbands should make family } \\
\text { planning decisions }\end{array}$ & $169(47.1)$ & $63(17.5)$ & $127(35.4)$ \\
\hline $\begin{array}{l}\text { Family planning can reduce the } \\
\text { rate of reproductive morbidity } \\
\text { and mortality in women }\end{array}$ & II4 (3I.8) & $72(20.0)$ & $173(48.2)$ \\
\hline $\begin{array}{l}\text { Condoms decrease sexual } \\
\text { pleasure }\end{array}$ & $187(52.1)$ & $92(25.6)$ & $80(22.3)$ \\
\hline
\end{tabular}

agreed that FP is good for the mother, as many as between one-quarter and one-third of these respondents opined that religion "is against" contraceptive use, that FP encourages infidelity/promiscuity, that it has many harmful side effects, that only the women should use contraceptives, and that the husband should be the one to take FP decisions.

Analysis of the association between the respondents' demographic/reproductive characteristics and uptake of contraception showed that "ever lost a child" $(P<0.01)$, awareness of place of FP service provision $(P<0.0001)$, approval of usage of contraception $(P<0.002)$, marital status $(P=0.001)$, and number of living children $(P<0.00000001)$ were all statistically significantly associated with "ever use" of contraception (Table 5).

Table 6 shows the results of the multivariate logistic regression analysis of "ever used contraceptives" and some selected variables. Women who were aware of a place of FP service provision were five times more likely to have ever used contraception than were those women who were not (odds ratio [OR] 5.81; 95\% CI 2.7-12.5; $P=0.001$ ). Women who approved of the use of contraceptives were about three times more likely to have ever used contraception than were those who did not approve of it (OR 2.8; 95\% CI 1.4-5.4; $P=0.001$ ). Women with tertiary level education were about one-and-a-half times more likely to have ever used contraception than were those with secondary level education. (OR 0.66; 95\% CI 0.36-1.22; $P=0.092$ ). Women who were married were also three times more likely to have ever used contraception than were women who were single, (OR 0.34; 95\% CI 0.18-0.64; $P=0.001$ ), while women with more than two children were also three times more likely to have ever used contraception than were women with less than two children (OR 0.30; 95\% CI 0.17-0.49; $P=0.001$ ).

\section{Discussion}

Two-thirds of respondents in this study signified their desire for more children, with an average of three to four children desired per woman. This supports a study ${ }^{10}$ in which the mean number of children desired was four. Desire for more children is an indication of a desire for future fertility among women. This may be due to the relaxation of some fertility reduction campaign efforts made during the military era of the 90 's and to the fact that maternal services are free of charge in most states in Nigeria, even at both primary and secondary levels of health care. With a current population of over 150 million and a growth rate of approximately $2.4 \%$ per annum, Nigeria is the most populous country in Africa. ${ }^{11}$ Population explosion causes a reduction in the "carrying 
Table 5 Association between respondents' demographic/reproductive characteristics and uptake of contraception

\begin{tabular}{|c|c|c|c|c|c|}
\hline \multirow[t]{3}{*}{ Variables } & \multicolumn{2}{|c|}{ Contraceptive ever-use } & \multirow{3}{*}{$\frac{\text { Total }}{\mathbf{N}(\%)}$} & \multirow[t]{3}{*}{$x^{2}$} & \multirow[t]{3}{*}{$P$-value } \\
\hline & Yes & No & & & \\
\hline & $\mathbf{N}(\%)$ & $\mathbf{N}(\%)$ & & & \\
\hline Ever lost a child & & & & 0.7 & $<0.01 *$ \\
\hline Yes & $8(15.4)$ & $44(84.6)$ & $52(14.5)$ & & \\
\hline No & $102(33.2)$ & $205(66.8)$ & $307(85.5)$ & & \\
\hline Awareness of place of FP service & & & & 24.2 & $<0.000 I^{*}$ \\
\hline Yes & $102(37.4)$ & $17 \mid(62.6)$ & $273(76.0)$ & & \\
\hline No & $8(9.3)$ & $78(90.7)$ & $86(24.0)$ & & \\
\hline Support/approval for usage & & & & 9.6 & $<0.002^{*}$ \\
\hline Yes & $98(34.5)$ & $186(65.5)$ & $284(79.1)$ & & \\
\hline No & $12(16.0)$ & $63(84.0)$ & $75(20.9)$ & & \\
\hline Nearness of FP service $(n=273)$ & & & & 0.3 & 0.9 \\
\hline$<5 \mathrm{~km}$ & $54(37.0)$ & $92(63.0)$ & $146(53.5)$ & & \\
\hline $5-10 \mathrm{~km}$ & $35(39.3)$ & $54(60.7)$ & $89(32.6)$ & & \\
\hline$>10 \mathrm{~km}$ & $13(34.2)$ & $25(65.8)$ & $38(13.9)$ & & \\
\hline Age group in years $\left(n=343 ;\right.$ nonresponse $\left.=16^{* *}\right)$ & & & & 1.12 & 0.6 \\
\hline$<20$ & $2(20.0)$ & $8(80.0)$ & $10(2.9)$ & & \\
\hline $20-40$ & $104(32.8)$ & $213(67.2)$ & $317(92.4)$ & & \\
\hline$>40$ & $4(25.0)$ & $12(75.0)$ & $16(4.7)$ & & \\
\hline Educational status & & & & 1.8 & 0.2 \\
\hline$<$ Secondary education & $16(23.9)$ & $5 I(76.1)$ & $67(18.7)$ & & \\
\hline$>$ Secondary education & $94(32.2)$ & $198(67.2)$ & $292(81.3)$ & & \\
\hline Marital status & & & & 11.9 & $0.00 I^{*}$ \\
\hline Single & $13(15.5)$ & $71(84.5)$ & $84(23.4)$ & & \\
\hline Ever married & $97(35.3)$ & $178(64.7)$ & $275(76.6)$ & & \\
\hline Number of living children & & & & 50.7 & $0.0000000 I^{*}$ \\
\hline 0 & $12(9.1)$ & $120(90.9)$ & $132(36.8)$ & & \\
\hline $1-2$ & $56(38.1)$ & 91 (61.9) & 147 (40.9) & & \\
\hline$>2$ & $42(52.5)$ & $38(47.5)$ & $80(22.3)$ & & \\
\hline
\end{tabular}

Notes: *Significant; **the nonresponses were not analyzed with the data.

Abbreviation: FP, family planning.

Table 6 Multivariate logistic regression analysis of "ever used contraceptives" and some selected variables

\begin{tabular}{|c|c|c|c|c|}
\hline Variables & $\begin{array}{l}\text { Contraceptive "ever used" } \\
\mathrm{N}(\%)\end{array}$ & Unadjusted odds ration & $95 \% \mathrm{Cl}$ & P-value \\
\hline \multicolumn{5}{|l|}{ Ever lost a child } \\
\hline Yes & $8(15.4)$ & 0.37 & $0.17-0.81$ & 0.005 \\
\hline No & $102(33.2)$ & & & \\
\hline \multicolumn{5}{|c|}{ Awareness of place of FP service } \\
\hline Yes & $102(37.4)$ & 5.81 & $2.70-12.53$ & 0.001 \\
\hline No & $8(9.3)$ & & & \\
\hline \multicolumn{5}{|c|}{ Approved of use of contraceptives } \\
\hline Yes & $98(34.5)$ & 2.8 & I.4-5.4 & 0.001 \\
\hline No & $12(16.0)$ & & & \\
\hline \multicolumn{5}{|l|}{ Educational status } \\
\hline$<$ Secondary education & 16(23.9) & 0.66 & $0.36-1.22$ & 0.092 \\
\hline$>$ Secondary education & $94(32.2)$ & & & \\
\hline \multicolumn{5}{|l|}{ Marital Status } \\
\hline Single & $13(\mid 5.5)$ & 0.34 & $0.18-0.64$ & 0.001 \\
\hline Ever married & $97(35.3)$ & & & \\
\hline \multicolumn{5}{|l|}{ Number of living children } \\
\hline 0 & $12(9.1)$ & 0.30 & $0.17-0.49$ & 0.001 \\
\hline $1-2$ & $56(38.1)$ & & & \\
\hline$>2$ & $42(52.5)$ & & & \\
\hline
\end{tabular}

Abbreviations: $\mathrm{Cl}$, confidence interval; $\mathrm{FP}$, family planning. 
capacity" of the ecosystem, bringing overexploitation, depletion, and pressure on natural resources, thus threatening public health. ${ }^{12}$ Committing a vast amount of resources into organized and well-targeted FP programs could help curtail this public health problem. The population of inner cities, which is likely to be high, would only surge as a result of the reported pattern of fertility desires. This also has the potential of maintaining the expansive pattern of population pyramids of Nigeria and other developing countries, in which a significant proportion of the population are in the dependent younger age group.

The majority of respondents in this study were aware of at least five modern methods of FP, however only about one-tenth $(13.1 \%)$ of respondents were currently using a modern method of FP. This high level of awareness and poor utilization pattern corroborates several other studies, ${ }^{13-16}$ in which awareness of contraception was high among majority of respondents, but only a minority used a method. Women in inner cities may be more exposed, have better access to media facilities, and may have visited nearby health facilities to obtain information on modern contraception and other reproductive health services. However, evidence has shown these are not sufficient to engender uptake of contraception. Low use of contraceptives could lead to unwanted pregnancies and its consequences, including psychological and physical health problems and unsafe abortions. This identified low utilization of contraception among this at-risk group of women calls for urgent intervention from both governmental agencies and NGOs. It should also inform policy makers and program planners on the need to target this very important sector of the society.

The most frequently used method among our respondents was the male condom. This had been reported by another similar study. ${ }^{17}$ Condoms are accessible, affordable, and easy to apply or use, and its side effects are minimal. The presence of numerous retail shops that characterized inner cities could also explain this trend. The cultural acceptability of use of condoms for HIV prevention has increased over the years ${ }^{18-20}$ and may be responsible for this high utilization rate of condoms.

Several reasons were given by respondents for nonuse of contraception. Ignorance and misinformation were leading barriers to contraceptive use. This corroborates several other studies. $^{21,22}$ Higher awareness would stimulate community members to look for more accurate information on desired methods from health care providers and consequently, promote correct and consistent use of the method. Alternately, gaps in women's knowledge of modern contraceptive methods and misperceptions about contraception could prevent higher uptake of effective contraceptives, including methods that would prevent both pregnancy and STIs.

The safety of contraceptives and fear of side effects were prominent perceived barriers to contraceptive use in this study, and this agreed with findings from some other studies. ${ }^{22,23}$ In another related study, one-third feared safety, and about two-thirds reported at least one side effect, while one-half considered FP ineffectiveness of method as barriers to use. ${ }^{24}$ In a similar study, the ability to tolerate the product's properties, including the look, feel, smell, color, and taste was a determinant of and barrier to use of contraceptives. ${ }^{25}$

Husband's opposition was also significant among the barriers to contraceptive use in this study, and this corroborates other studies. ${ }^{22,23}$ Research on the reasons for FP nonuse in Nigeria generally points to women's perceived lack of need for contraception (as was reported in our study), fear of side effects, and opposition to contraception on personal or religious grounds. ${ }^{17,26}$ As a result of the difficulties with modern contraceptive methods discussed above, young women were more likely to rely on traditional methods, such as periodic abstinence, withdrawal, or charms and herbal mixtures from traditional healers, ${ }^{27-29}$ and this is also supported by the findings from the current study. This finding provides evidence for the need of greater involvement of men in contraception and other reproductive health and rights issues affecting their spouse and family.

Inner-city people are more likely to be educated, have access to FP services, and lay little emphasis on traditional and cultural values, due to westernization. However, contrary to the National Demographic Health Survey, Nigeria (NDHS) $2008,{ }^{8}$ in which only one-quarter of respondents signified that they desired a greater number of children, the relatively higher proportion of desiring more children in this study, suggests that fertility issues have not been resolved adequately in Nigeria, probably due to the various barriers. The persistently high fertility in Nigeria despite FP programs suggests that there are yet undetermined barriers to contraceptive use and factors associated with contraception that has been rendering the current strategy less effective.

The associations found between some of the variables and the results of the regression analysis done in this study suggest awareness of a place of FP service provision, respondent's approval of the use of contraceptives, higher education status, and being married as possible predictors 
of use of modern contraceptives. If a woman knows of health facilities where she can purchase contraceptives, most especially at an affordable price, it is likely that she would see out contraception. Better educated women are also more likely to seek information about reproductive health and are possibly more likely to have been empowered to convince their husbands of the need for contraception, even in instances where men were reported to initially constitute obstacles to contraception.

In addition, married women are more likely to be current users since they are formally married and are traditionally expected to be sexually active, reflecting the cultural influences on sexuality and contraception. For reasons of health concern, the thinking that they have successfully completed their desired family size, and/or for economic reasons, women of reproductive age may also decide to use contraceptives. All these factors should be considered when planning fertility reduction programs in Nigeria.

\section{Conclusion}

Several socioeconomic and health facility-related barriers have been reported in this study. These might have been responsible for the low prevalence of modern contraceptive use among women living in the inner city area of an urban location in Nigeria, despite high awareness and favorable indicators for increased levels of use. Because many of these barriers are removable/modifiable, it is recommended that a community-based behavioral-change communication program be instituted, aimed at improving the awareness and perceptions of women with respect to desire for more children, at bridging the knowledge gaps about contraceptive methods, and at changing the deep-seated negative beliefs related to contraceptive use in Nigeria.

\section{Disclosure}

The authors report no conflicts of interest in this work.

\section{References}

1. United Nations Population Fund. The State of the World Population 1999: 6 Billion. A Time for Choices. NY, New York: United Nations Population Fund; 1999.

2. Randrianasolo B, Swezey T, Van Damme K, et al; MAD STI Prevention Group. Barriers to the use of modern contraceptives and implications for woman-controlled prevention of sexually transmitted infections in Madagascar. J Biosoc Sci. 2008;40(6):879-893.

3. Oye-Adeniran BA, Adewole IF, Umoh AV, Ekanem EE, Gbadegesin A, Iwere N. Community-based survey of unwanted pregnancy in southwestern Nigeria. Afr J Reprod Health. 2004;8(3):103-115.

4. Okonofua FE, Odimegwu C, Ajabor H, Daru PH, Johnson A. Assessing the prevalence and determinants of unwanted pregnancy and induced abortion in Nigeria. Stud Fam Plann. 1999;30(1):67-77.
5. Creanga AA, Gillespie D, Karklins S, Tsui AO. Low use of contraception among poor women in Africa: an equity issue. Bull World Health Organ. 2011;89(4):258-266.

6. United Nations Population Division. World Contraceptive Use 2003. New York, NY: United Nations; 2004.

7. Olawuyi JF. Choosing the study subjects and sampling. In: Daniel WW, editor. Biostatistics, a Foundation Course in Health Sciences. Ibadan: Yotson Consult; 1996:110-118.

8. National Population Commission (NPC). Nigeria Demographic and Health Survey 2006. Calverton, MD: NPC and ICF Macro; 2006.

9. Oyedokun AO. Determinants of contraceptive usage: lessons from women in Osun State, Nigeria. Journal of Humanities and Social Sciences. 2007;1(2):1-14.

10. Umoh AV, Abah GM, Ekanem US. A study of fertility intentions of women in Uyo Nigeria. J Public Health Epidemiol. 2012;4(1):14-18.

11. prb.org [homepage on the Internet]. Nigeria. Population Reference Bureau; 2007 [cited Jun 2012]. Available from: http://www.prb.org/ Countries/Nigeria.aspx. Accessed July 27, 2013.

12. Hinrichsen D, Robey B. Population and the environment: the global challenge. Popul Rep. 2000;15.

13. Arowojolu AO, Ilesanmi AO, Roberts OA, Okunola MA. Sexuality, contraceptive choice and AIDS awareness among Nigerian undergraduates. Afr J Reprod Health. 2002;6(2):60-70.

14. Rutstein SO. Effects of preceding birth intervals on neonatal, infant and under-five years mortality and nutritional status in developing countries: evidence from the demographic and health surveys. Int $J$ Gynaecol Obstet. 2005;89 Suppl 1:S7-S24.

15. Conde-Agudelo A, Balizán JM. Maternal morbidity and mortality associated with interpregnancy interval: cross sectional study. $B M J$. 2000;321:1255-1259.

16. Gillespie DG. Whatever happened to family planning, and, for that matter, reproductive health? Int Fam Plan Perspect. 2004;30(1):34-38.

17. Oye-Adeniran BA, Adewole IF, Odeyemi KA, Ekanem EE, Umoh AV. Contraceptive prevalence among young women in Nigeria. $J$ Obstet Gynaecol. 2005;25(2):182-185.

18. Brady M. Preventing sexually transmitted infections and unintended pregnancy, and safeguarding fertility: triple protection needs of young women. Reprod Health Matters. 2003;11(22):134-141.

19. Cleland J, Ali MM. Sexual abstinence, contraception, and condom use by young African women: a secondary analysis of survey data. Lancet. 2006;368(9549):1788-1793.

20. Maharaj P, Cleland J. Condoms become the norm in the sexual culture of college students in Durban, South Africa. Reprod Health Matters. 2006;14(28):104-112.

21. Randrianasolo B, Swezey T, Van Damme K, et al; MAD STI Prevention Group. Barriers to the use of modern contraceptives and implications for woman-controlled prevention of sexually transmitted infections in Madagascar. J Biosoc Sci. 2008;40(6):879-893.

22. Casterline JB, Sinding SW. Unmet need for family planning in developing countries and implications for population policy. Popul Dev Rev. 2000;26(4):691-723.

23. Nagase T, Kunii O, Wakai S, Khaleel A. Obstacles to modern contraceptive use among married women in southern urban Maldives. Contraception. 2003;68(2):125-134.

24. Aryeetey R, Kotoh AM, Hindin MJ. Knowledge, perceptions and ever use of modern contraception among women in the Ga East District, Ghana. Afr J Reprod Health. 2010;14(4 Spec no):26-31.

25. Severy LJ, Newcomer S. Critical issues in contraceptive and STI acceptability research. $J$ Soc Issues. 2005;61(1):45-65.

26. Orji EO, Onwudiegwu U. Prevalence and determinants of contraceptive practice in a defined Nigerian population. J Obstet Gynaecol. 2002; 22(5):540-543.

27. Nguyen HN, Liamputtong P, Murphy G. Knowledge of contraceptives and sexually transmitted diseases and contraceptive practices amongst young people in Ho Chi Minh City, Vietnam. Health Care Women Int. 2006;27(5):399-417. 
28. Otoide VO, Oronsaye F, Okonofua FE. Why Nigerian adolescents seek abortion rather than contraception: evidence from focus-group discussions. Int Fam Plann Perspect. 2001;27(2):77-81.
29. Wood K, Jewkes R. Blood blockages and scolding nurses: barriers to adolescent contraceptive use in South Africa. Reprod Health Matters. 2006;14(27):109-118

International Journal of Women's Health

\section{Publish your work in this journal}

The International Journal of Women's Health is an international, peerreviewed open-access journal publishing original research, reports, editorials, reviews and commentaries on all aspects of women's healthcare including gynecology, obstetrics, and breast cancer. The manuscript management system is completely online and includes a very quick and fair peer-review system, which is all easy to use. Visit http://www.dovepress.com/testimonials.php to read real quotes from published authors.

Submit your manuscript here: http://www.dovepress.com/international-journal-of-womens-health-journal 